\title{
Aplicação curativa de fungicidas e seu efeito sobre a expansão de lesão da mancha-amarela do trigo
}

\author{
Curative sprays of fungicides and their effect on lesion expansion of the wheat tan spot
}

\author{
Camila Ranzi ${ }^{\mathrm{I}}$ Carlos Alberto Forcelini ${ }^{\mathrm{II}}$
}

\section{RESUMO}

A mancha-amarela é uma das principais doenças foliares do trigo no Brasil, com danos de até $80 \%$ sobre o rendimento de grãos. A expansão da lesão é um importante componente da epidemia da mancha-amarela, porém ainda pouco estudado, especialmente quanto ao efeito de aplicações de fungicida em fase pós-sintoma. Para conhecer como diferentes grupos de fungicidas agem sobre a expansão da lesão, e assim otimizar o manejo da doença, quatro ensaios foram realizados na Universidade de Passo Fundo (UPF), em 2011. Os trabalhos foram organizados em delineamento de blocos casualizados, com quatro repetições, e conduzidos em câmara de crescimento com controle de temperatura e luz. Em dois deles, um fungicida triazol (propiconazol) e uma estrobilurina (azoxistrobina), bem como ambos em mistura, foram aplicados em intervalos crescentes de um até 12 dias após a inoculação das plantas dos cultivares 'Fundacep Horizonte'e 'Quartzo'. Com base em medições do tamanho da lesão, a estrobilurina não diminuiu a taxa de expansão da lesão $\left(0,176\right.$ a $0,180 \mathrm{~mm}^{2}$.dia $\left.{ }^{-1}\right)$ em relação à testemunha $(0,175$ a $0,184 \mathrm{~mm}^{2}$.dia $\left.{ }^{-1}\right)$, enquanto o triazol $\left(0,080 \mathrm{~mm}^{2}\right.$.dia $\left.{ }^{-1}\right)$ e a mistura $\left(0,060\right.$ a $0,080 \mathrm{~mm}^{2}$.dia $\left.{ }^{-1}\right)$ o fizeram quando aplicados em períodos inferiores a 10 ou 12 dias após a inoculação. Em outros dois ensaios, fungicidas comerciais (epoxiconazol, propiconazol, tebuconazol, azoxistrobina, piraclostrobina, ciproconazol + azoxistrobina, epoxiconazol + piraclostrobina, protioconazol + trifloxistrobina e tebuconazol + trifloxistrobina) foram aplicados às plantas aos três, cinco ou oito dias após a inoculação. Aos cinco dias, epoxiconazol, propiconazol e protioconazol + trifloxistrobina reduziram a taxa de progresso da lesão (0,07 a $0,14 \mathrm{~mm}^{2}$.dia $\left.\mathrm{di}^{-1}\right)$ em relação à testemunha $\left(0,29 \mathrm{~mm}^{2}\right.$.dia $\left.\mathrm{d}^{-1}\right)$. Aos oito dias, não houve diferença entre os fungicidas e a testemunha. O tamanho final das lesões foi menor (3,76 a 5,89 $\left.\mathrm{mm}^{2}\right)$ nas plantas tratadas com tebuconazol + trifloxistrobina, protioconazol + trifloxistrobina, tebuconazol, epoxiconazol + piraclostrobina e propiconazol, sendo maior $\left(8,46\right.$ a $\left.11,70 \mathrm{~mm}^{2}\right)$ para ciproconazol + azoxistrobina, azoxistrobina, epoxiconazol e piraclostrobina, que não diferiram da testemunha. Tais resultados evidenciam a dificuldade em restringir o progresso da mancha-amarela após seu estabelecimento nas plantas e enfatiza a necessidade de estratégias de manejo preventivas.

Palavras-chave: Pyrenophora tritici-repentis, triazóis, estrobilurinas.

\section{ABSTRACT}

Tan spot is one of the main diseases of wheat in Brazil reducing grain yield up to $80 \%$. Although the lesion expansion is an important component of the epidemics, there are few studies on its control by curative sprays of fungicide. To know how different fungicides may control lesion expansion and to improve disease management, four assays were carried out at the Universidade de Passo Fundo (UPF) in 2011. All assays were organized as randomized blocks, with four replicates, inside a growth chamber with control of light and temperature. In two assays a triazole (propiconazole) and a strobylurin (azoxystrobin) fungicides, as well as their mixture, were sprayed from one to 12 day intervals after inoculation of the wheat cultivars 'Fundacep Horizonte' and 'Quartzo'. Based upon measurements of the lesion size, the strobylurin did not reduce the rate of lesion growth (0.176 to 0.180 $\mathrm{mm}^{2}$.day $\left.{ }^{-1}\right)$ in comparison to the non-sprayed control (0.175 to $0.184 \mathrm{~mm}^{2}$. day $\left.^{-1}\right)$, whereas the triazole $\left(0.080 \mathrm{~mm}^{2}\right.$. day-1) and the fungicide mix ( 0.060 to $0.080 \mathrm{~mm}^{2}$.day-1) did it if sprayed within 10 or 12 days after inoculation. In two other assays, commercial fungicides (epoxiconazole, propiconazole, tebuconazole, azoxystrobin, pyraclostrobin, cyproconazole + azoxystrobin, epoxiconazole + pyraclostrobin, protioconazole + trifloxystrobin and tebuconazole + trifloxystrobin) were sprayed onto plants at three, five and eight days after inoculation. Spraying of the fungicides epoxiconazole, propiconazole, and protioconazole + trifloxystrobin at five days reduced the rate of lesion expansion (0.07 to $0.14 \mathrm{~mm}^{2}$.day $\left.{ }^{-1}\right)$ over the control non-sprayed plants $(0.29$ $\mathrm{mm}^{2}$.day ${ }^{-1}$ ). Fungicide applications eight days had no effect on the rate of progress of lesions. The final lesion size was smaller (3.76 to $5.89 \mathrm{~mm}^{2}$ ) on plants sprayed with tebuconazole + trifloxystrobin, protioconazole + trifloxystrobin, tebuconazol, epoxiconazole + pyraclostrobin, and propiconazole, but higher (8.46 to $\left.11.70 \mathrm{~mm}^{2}\right)$

IUniversidade de Passo Fundo (UPF), Passo Fundo, RS, Brasil.

"Faculdade de Agronomia e Medicina Veterinária, UPF, 99001-970, Passo Fundo, RS, Brasil. E-mail: camila_ranzi@hotmail.com. Autor para correspondência. 
for cyproconazole + azoxystrobin, azoxystrobin, epoxiconazole, and pyraclostrobin, which did not differ from the non-sprayed control. These results show how difficult is to limit tan spot increase after disease establishment and indicate that is management requires the adoption of preventive control strategies.

Key words: Pyrenophora tritici-repentis, triazoles, strobylurins.

\section{INTRODUÇÃO}

As doenças têm grande relevância para a cultura do trigo no Sul do Brasil, sendo causadoras de extensos prejuízos à produção de grãos. PICININI \& FERNANDES (1995), em 12 anos de experimentação com a cultura do trigo, registraram dano anual médio de 44,6\%, o equivalente a $1.152 \mathrm{~kg}$ de grãos por hectare. Entre as doenças foliares do trigo, a manchaamarela, causada pelos fungos Drechslera triticirepentis (Died) Shoemaker e Drechslera siccans (Drechsler) Shoem, aumentou significativamente em importância nos últimos anos, sendo encontrada em mais de $60 \%$ dos levantamentos efetuados em campo (REIS et al., 2011).

As principais fontes de inóculo para a mancha-amarela são as sementes infectadas, os restos culturais e as plantas de azevém, hospedeiro alternativo, presentes na lavoura ou próximas a ela (REIS et al., 2011). Os ascósporos e conídios provenientes das fontes de inóculo são os responsáveis pelo estabelecimento das lesões iniciais. Posteriormente, a produção de toxinas que causam clorose e necrose (MANNING \& CIUFFETTI, 2005) resulta no crescimento das lesões e contribui para o aumento da epidemia.

A importância da expansão da lesão como componente de epidemias, especialmente por fungos necrotróficos, foi demonstrada por BERGAMIM FILHO \&AMORIM (1996) e BERGER et al. (1997). A expansão de lesão reflete a ação infecciosa, interna, do patógeno nos tecidos adjacentes, especialmente quando as condições ambientais não são favoráveis à esporulação, dispersão do inóculo e indução de novas infecções.

O tamanho e a taxa de expansão da lesão são mais utilizados para avaliar a resistência genética de cultivares e a agressividade de estirpes ou raças de bactérias e fungos fitopatogênicos (JOHNSON \& TAYLOR, 1976; LUO \& ZENG, 1995; BERGER et al., 1997). Entretanto, como componente do processo epidêmico da mancha-amarela, a expansão de lesão deve ser considerada na definição de estratégias de controle para a doença. As relações ou interações da expansão de lesão com o tratamento químico, por exemplo, são pouco conhecidas.
Em trigo, a aplicação foliar de fungicidas para controle da mancha-amarela é indicada após o aparecimento dos primeiros sintomas, quando atingido o limiar de dano econômico (REIS et al., 2011) ou a incidência de 70\% (REUNIÃO, 2009). Em campo, o desempenho dos produtos utilizados em fase pós-sintoma é insatisfatório, devido, possivelmente, ao não controle da expansão da lesão da manchaamarela. O presente trabalho teve por objetivo avaliar a ação curativa de fungicidas sobre o crescimento das lesões da mancha-amarela, a fim de aperfeiçoar o manejo da doença e aumentar a rentabilidade da cultura do trigo.

\section{MATERIAL E MÉTODOS}

Os trabalhos foram realizados na Universidade de Passo Fundo, no período de agosto a novembro de 2011. Ao todo foram quatro ensaios, dois para avaliação do controle curativo da manchaamarela com fungicida triazol e estrobilurina, e outros dois para um comparativo dos fungicidas comerciais. Todos os ensaios foram organizados como blocos casualizados, com quatro repetições, sendo cada repetição um vaso com quatro plantas. As plantas foram mantidas em câmara de crescimento com controle de fotoperíodo (12 h luz, 12 h escuro) e temperatura $\left(21 \pm 1^{\circ} \mathrm{C}\right)$.

Controle curativo com fungicida triazol e estrobilurina Dois ensaios foram direcionados ao estudo do controle curativo da mancha-amarela por fungicidas dos grupos químicos triazol e estrobilurina. As plantas de trigo (cultivares 'Fundacep Horizonte' e 'Quartzo') foram crescidas em copos plásticos com capacidade para $500 \mathrm{~mL}$, contendo uma mistura de solo e vermiculita na proporção 3:1 (v:v). No estádio de três folhas expandidas, as plantas de trigo foram inoculadas com uma suspensão de esporos $\left(3 \times 10^{3}\right.$ conídios. $\mathrm{mL}^{-1}$ ) obtida a partir de colônias puras de D. tritici-repentis em meio V8-Ágar. A suspensão foi aplicada até o ponto de escorrimento, através aspersor manual com capacidade para $500 \mathrm{~mL}$ de inóculo. Logo após a inoculação as plantas foram cobertas com sacos plásticos por 24 horas.

Os tratamentos avaliados corresponderam a uma testemunha não tratada, à aplicação de um fungicida triazol (propiconazol, 0,5L.ha-1 do produto comercial Tilt ${ }^{\circledR}$ ), um fungicida do grupo químico das estrobilurinas (azoxistrobina, 0,3L.ha ${ }^{-1}$ do produto comercial Priori $\left.^{\circledR}\right)$ e à mistura dos dois (0,2L.ha ${ }^{-1}$ de Tilt + 0,3L.ha ${ }^{-1}$ de Priori). Nas aplicações com 
azoxistrobina utilizou-se, também, o óleo mineral Nimbus, a 0,5\% do volume de água. As aplicações de fungicida foram realizadas com aspersor manual com capacidade de 500mL, a 1, 2, 4, 8 e 12 dias após a inoculação (DAI). As plantas testemunhas foram pulverizadas apenas com água. Na repetição desse ensaio, os intervalos de aplicação foram alterados para 1, 2, 5, 7 e 10 dias, devido à senescência das folhas.

Comparativo de fungicidas comerciais

Dois outros ensaios foram destinados à avaliação de nove fungicidas comerciais (Tabela 1), quanto ao seu efeito sobre a expansão de lesão da mancha-amarela, em aplicações curativas. As plantas de trigo (Fundacep Horizonte) foram cultivadas em vasos e inoculadas como descrito anteriormente. Para simular uma aplicação em campo, os vasos foram dispostos sobre o solo e as plantas pulverizadas com os fungicidas. Utilizou-se um pulverizador costal, pressurizado com CO2, dotado de barra com $3 \mathrm{~m}$ de largura e pontas de jato plano simples TT 110015, ajustado a um volume de 150L.ha-1 ${ }^{-1}$ As aplicações foram realizadas aos 3, 5 e 8 dias após a inoculação, respeitando as doses e condições de uso de cada produto. Nesses ensaios, também, a testemunha recebeu aplicação com água.

\section{Avaliações}

Em todos os experimentos as avaliações foram iniciadas três dias após a inoculação. Deu-se preferência à terceira folha expandida, cujas lesões foram numeradas com marcador permanente para avaliações sequenciais, a cada dois dias. As lesões foram medidas quanto ao comprimento (C) e largura (L) da área necrosada, com um paquímetro digital de precisão de 0,01 $\mathrm{mm}$. Aárea foi estimada em $\mathrm{mm}^{2}$, pela fórmula CxLx0,69, em que valor 0,69 corresponde a um fator de correção obtido pela comparação do produto de C x L com a área real medida em um integralizador digital de área foliar (Licor).

\section{Análise estatística}

Os resultados foram submetidos à análise de variância e regressão linear pelo modelo $\mathrm{y}=\mathrm{a}+$ bx, em que y é a área da lesão, x o tempo em dias, a e b parâmetros da equação, em que b também corresponde à taxa de expansão da lesão. No estudo comparativo dos fungicidas comerciais utilizou-se o teste de Scott-Knott, ao nível de 5\% de probabilidade de erro, para comparar as taxas de expansão das lesões $\left(\mathrm{mm}^{2}\right.$. $\left.\mathrm{dia}^{-1}\right)$ e o tamanho final das lesões $\left(\mathrm{mm}^{2}\right)$ entre os tratamentos utilizados.

\section{RESULTADOS E DISCUSSÃO}

Controle curativo com fungicida triazol e estrobilurina Os primeiros sintomas da mancha-amarela se tornaram visíveis após três dias da inoculação. O tamanho médio inicial das lesões variou de 0,78 $\mathrm{mm}^{2}$ (cultivar 'Quartzo') a 0,89 $\mathrm{mm}^{2}$ (Fundacep Horizonte). Aos 12 dias após a inoculação, as lesões atingiram até 1,91 $\mathrm{mm}^{2}$ (Quartzo) e 11,77 $\mathrm{mm}^{2}$ (Fundacep Horizonte), representando incrementos de 2,45 e 13,22 vezes, respectivamente.

Na média das duas cultivares, a aplicação curativa da estrobilurina não afetou a taxa de expansão de lesão da mancha-amarela, que foi de $0,176 \mathrm{~mm}^{2}$. $\mathrm{dia}^{-1}$ no ensaio 1 (Figura 1 -A) e $0,180 \mathrm{~mm}^{2}$. dia ${ }^{-1}$ no ensaio 2 (Figura 1-B), contra 0,175 e 0,184mm². $\mathrm{dia}^{-1}$ da testemunha, respectivamente. Em ambos os ensaios as regressões referentes à estrobilurina não foram significativas ( $\mathrm{p}>0,05)$ e os coeficientes de determinação baixos $\left(\mathrm{R}^{2}=0,0362\right.$ a 0,0074$)$, indicando ausência de efeito. Com o uso do triazol, a taxa de expansão de lesão foi menor no início $\left(0,08 \mathrm{~mm}^{2}\right.$.

Tabela 1 - Fungicidas e adjuvantes comparados quanto ao progresso das lesões da mancha-amarela em trigo.

\begin{tabular}{lccc}
\hline Ingrediente ativo & Dose $\left(\right.$ L.ha $\left.{ }^{-1}\right)$ & Adjuvante & Dose (L.ha $\left.{ }^{-1}\right)$ \\
\hline Propiconazol & 0,100 & - & \\
Tebuconazol & 0,120 & - & \\
Epoxiconazol & 0,094 & - & 0,600 \\
Azoxistrobina & 0,075 & Nimbus & 0,500 \\
Piraclostrobina & 0,175 & Assist & 0,600 \\
Ciproconazol + azoxistrobina & $0,024+0,060$ & Nimbus & 0,500 \\
Epoxiconazol + piraclostrobina & $0,037+0,100$ & Assist & 0,400 \\
Tebuconazol + trifloxistrobina & $0,120+0,060$ & Aureo & 0,400 \\
Protioconazol + trifloxistrobina & $0,079+0,067$ & Aureo & \\
\hline
\end{tabular}




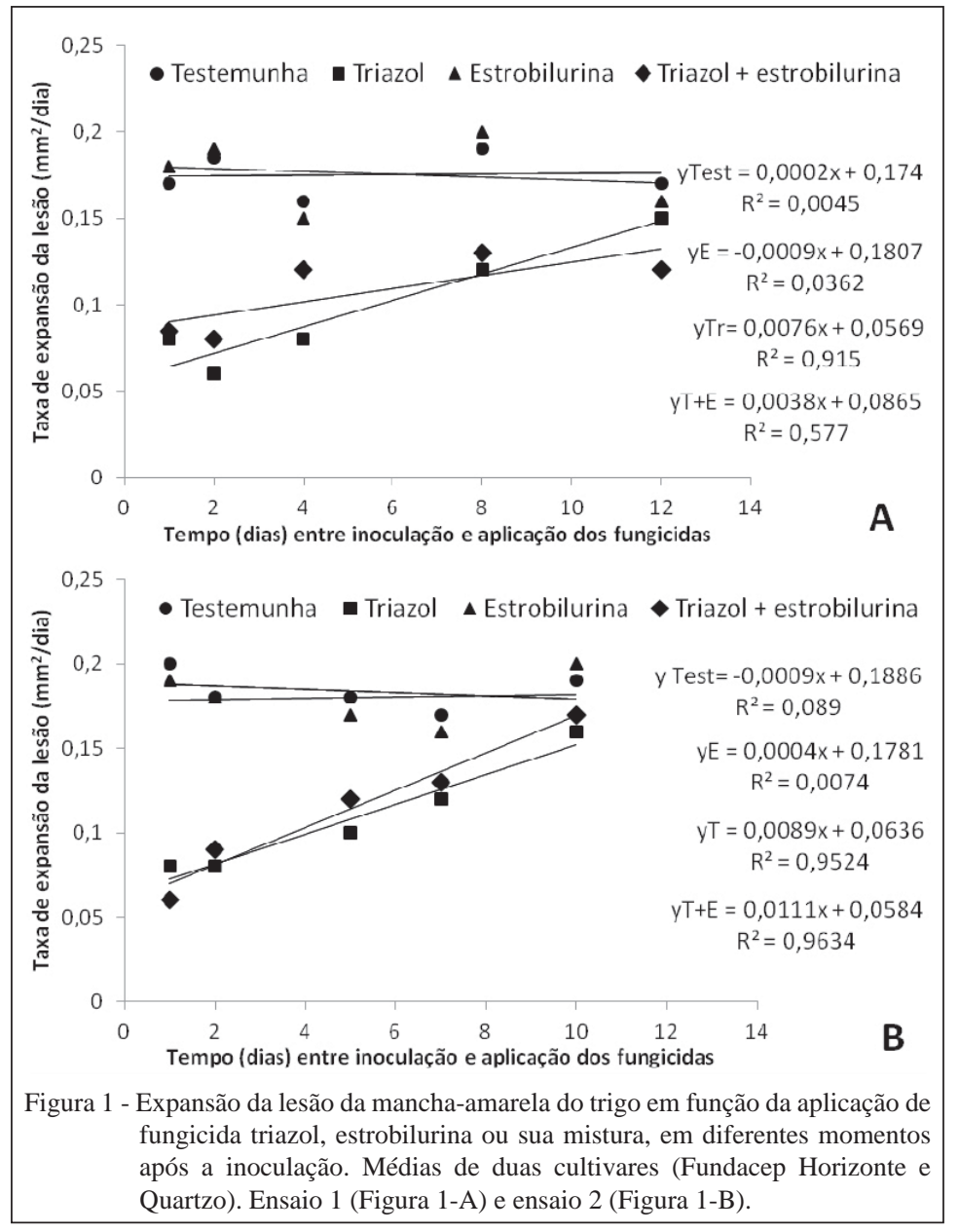

dia $^{-1}$ ), demonstrando eficácia deste tipo de fungicida no controle da doença. O efeito da mistura de ambos os fungicidas acompanhou o comportamento do triazol, especialmente no ensaio 2 (Figura 1, B).

À medida que aumentou o tempo, em dias, entre a inoculação das plantas com o patógeno e as subsequentes aplicações do triazol, as taxas de expansão da lesão também aumentaram, indicando diminuição na ação do fungicida. Os modelos matemáticos foram significativos $(\mathrm{p}<0,01)$ e os coeficientes de determinação altos $\left(\mathrm{R}^{2}=0,915\right.$ a 0,9524). Quando o triazol foi aplicado aos 10 (Figura 1-B) ou 12 dias (Figura 1-A) após a inoculação, o seu comportamento foi semelhante ao da estrobilurina, ou seja, não foi mais capaz de restringir a expansão de lesão da mancha-amarela.

Comparativo de fungicidas comerciais

Na avaliação dos fungicidas comerciais, houve interação significativa com a época de aplicação (três, cinco ou oito dias após a inoculação) (Tabela 2). Aos três dias, exceto a mistura de ciproconazol + azoxistrobina, todos os demais diferiram da testemunha pelo teste de Scott-Knott a 5\% de probabilidade de erro. Na aplicação aos cinco dias, apenas epoxiconazol, propiconazol e protioconazol + trifloxistrobina reduziram a taxa de aumento das lesões. Aos oito dias, nenhum fungicida testado foi capaz de conter o aumento das manchas foliares.

O tamanho final das lesões, medido 16 dias após a inoculação das plantas (Figura 2), separou os fungicidas comerciais em dois grupos pelo teste de Scott-Knott $(\mathrm{p}<0,05)$. No primeiro, constituído pelos fungicidas ciproconazol + azoxistrobina, azoxistrobina, epoxiconazol e piraclostrobina, que não diferem da testemunha (tratamento 5 na Figura 2), a área da lesão variou de 7,60 a $11,70 \mathrm{~mm}^{2}$. No segundo grupo, com os fungicidas tebuconazol + trifloxistrobina, protioconazol + trifloxistrobina, tebuconazol, epoxiconazol + piraclostrobina e propiconazol, a área final da lesão foi menor (3,76 e $5,79 \mathrm{~mm}^{2}$ ). 
Tabela 2 - Taxa de crescimento da lesão $\left(\mathrm{mm}^{2} \cdot \mathrm{dia}^{-1}\right)$ da mancha-amarela do trigo, cultivar 'Fundacep Horizonte’, em função de uma aplicação de fungicida, aos 3, 5 ou 8 dias após a inoculação. UPF, Passo Fundo, 2011

\begin{tabular}{|c|c|c|c|c|}
\hline \multirow[b]{2}{*}{ Fungicida } & \multirow[b]{2}{*}{ Dose $\left(\right.$ L.ha $\left.{ }^{-1}\right)$} & \multicolumn{3}{|c|}{--- Taxa de crescimento da lesão $\left(\mathrm{mm}^{2} . \mathrm{dia}^{-1}\right)$} \\
\hline & & $3^{*}$ & 5 & 8 \\
\hline Testemunha & - & $0,29 \mathrm{a}^{1}$ & 0,29 a & $0,30 \mathrm{~ns}$ \\
\hline Ciproconazol + azoxistrobina & $0,024+0,06$ & 0,38 a & 0,23 a & 0,20 \\
\hline Epoxiconazol + piraclostrobina & $0,037+0,1$ & $0,14 \mathrm{~b}$ & $0,22 \mathrm{a}$ & 0,23 \\
\hline Azoxistrobina & 0,075 & $0,20 \mathrm{~b}$ & 0,21 a & 0,21 \\
\hline Piraclostrobina & 0,175 & $0,20 \mathrm{~b}$ & 0,17 a & 0,29 \\
\hline Tebuconazol & 0,12 & $0,16 \mathrm{~b}$ & 0,17 a & 0,17 \\
\hline Tebuconazol + trifloxistrobina & $0,12+0,06$ & $0,14 \mathrm{~b}$ & 0,16 a & 0,16 \\
\hline Epoxiconazol & 0,094 & $0,20 \mathrm{~b}$ & $0,14 \mathrm{~b}$ & 0,19 \\
\hline Propiconazol & 0,1 & $0,18 \mathrm{~b}$ & $0,12 \mathrm{~b}$ & 0,18 \\
\hline Protioconazol + trifloxistrobina & $0,079+0,067$ & $0,12 \mathrm{~b}$ & $0,07 \mathrm{~b}$ & 0,17 \\
\hline C.V. (\%) & & 13,21 & 18,15 & 18,64 \\
\hline
\end{tabular}

${ }^{1}$ Médias seguidas por mesmas letras na coluna não diferem entre si pelo teste de Scott-Knott a 5\% de probabilidade do erro. Análise com dados transformados segundo $\mathrm{x}=1 / \mathrm{vx}$.

* Intervalo em dias, da aplicação dos fungicidas.

A utilização isolada da estrobilurina não influenciou a taxa de progresso das lesões, ou seja, não restringiu esse processo. Esse fato é compreensível, uma vez que os fungicidas desse grupo químico agem principalmente sobre o esporo, inibindo sua formação (ação anti-esporulante) ou germinação (AZEVEDO, 2007). A expansão de lesão é mediada pela produção de toxinas que matam os tecidos adjacentes ao sítio de infecção, portanto, é um processo comum entre fungos necrotróficos (BERGER et al., 1997). Fungicidas do grupo químico das estrobilurinas também são menos sistêmicos que os triazóis (AZEVEDO, 2007), o que limita sua ação em tecidos mortos, onde os patógenos necrotróficos são mais ativos.

O fungicida triazol reduziu o processo de expansão da lesão da mancha-amarela somente quando aplicado nos primeiros dias após a infecção. Após 10 ou 12 dias, a ação do fungicida não influencia mais nas infecções existentes. Resultados semelhantes foram obtidos por MENEGON et al. (2005) com manchas foliares em cevada. Esse fato reforça a importância do momento para iniciar a aplicação dos fungicidas, como já salientado por REIS \& CASA (2007), como um dos fatores que mais afeta a eficácia do controle químico de doenças. Portanto, em cultivares de trigo suscetível à mancha-amarela, a aplicação de fungicidas deve ser preventiva ou, no máximo, logo depois de detectados os sintomas iniciais.

Indicações para aplicação de fungicidas em trigo são, geralmente, baseadas na incidência da doença em folhas ou plantas. No caso das manchas foliares, este índice pode ser tão alto quanto 70\% (REUNIÃO, 2009). Pelos resultados obtidos neste trabalho, considera-se que este percentual compromete a ação dos fungicidas em parar ou diminuir o processo de expansão da lesão. Portanto, sugere-se que as indicações para aplicação de fungicidas para manchas foliares em trigo sejam revistas, especialmente para cultivares de trigo suscetível à mancha-amarela.

Em conclusão, a aplicação curativa de fungicidas tem ação limitada sobre a expansão da lesão, visto que este processo é mediado pela produção de toxinas. O controle parcial deste componente da epidemia só é possível com fungicidas triazóis aplicados nos primeiros dias após a infecção. Há a necessidade de um manejo preventivo para as 


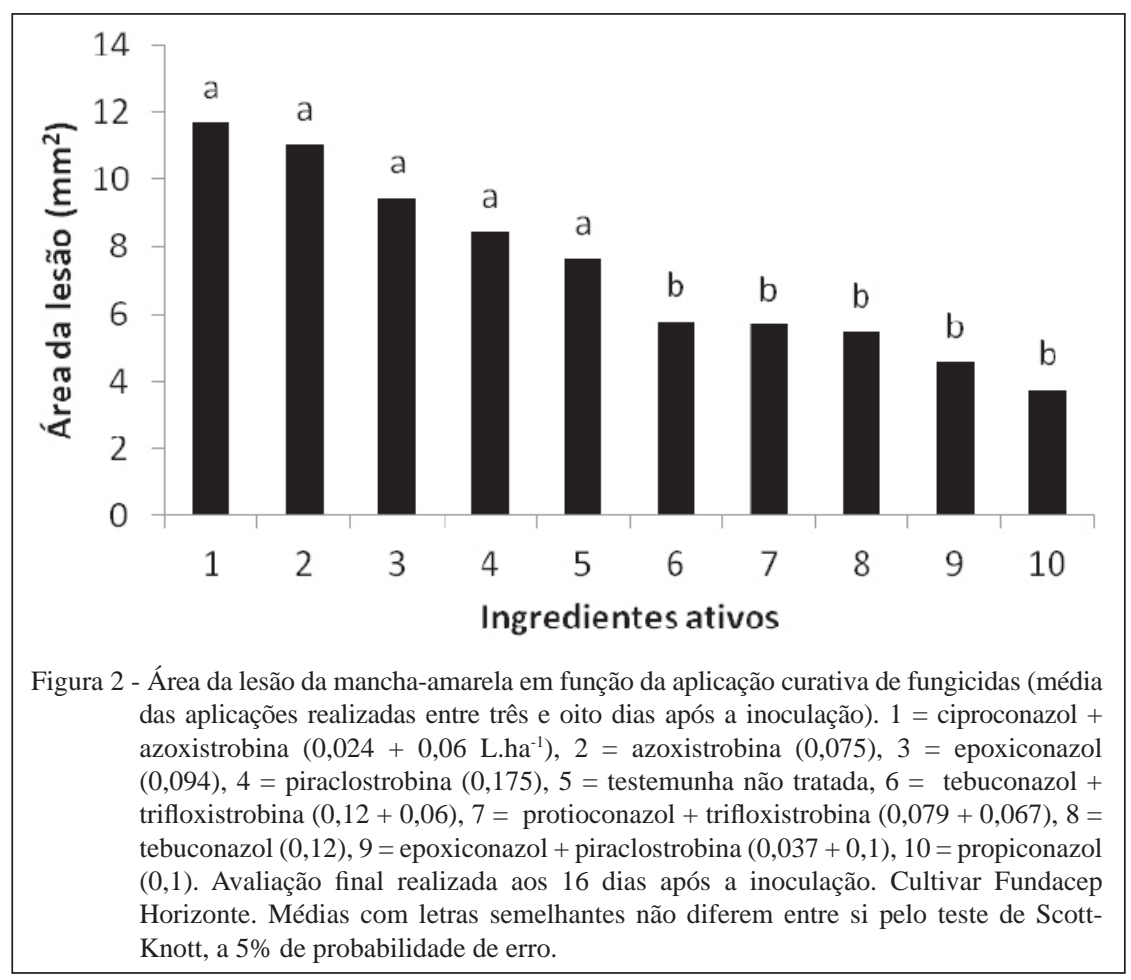

manchas foliares, com a inclusão de cultivares menos suscetíveis, da rotação de culturas, do tratamento de sementes e da aplicação de fungicida, no máximo, até o aparecimento dos sintomas iniciais da doença.

\section{REFERÊNCIAS}

AZEVEDO, L.A.S. Fungicidas sistêmicos: teoria e prática. Campinas: Emopi, 2007. 290 p.

BERGER, R.D., BERGAMIM FILHO, A.; AMORIM, L. Lesion expansion as an epidemic component. Phytopathology, v.87, p.1005-1013, 1997. Disponível em: <http://dx.doi.org/10.1094/ PHYTO.1997.87.10.1005>. Acesso em: 30 nov. 2011. doi: 10.1094/PHYTO.1997.87.10.1005.

BERGAMIN FILHO, A. \& AMORIM, L. Doenças de plantas tropicais e controle econômico. São Paulo: Ed. Agronômica Ceres, 1996. 289p.

JOHNSON, R.; TAYLOR, A.J. Spore yield of pathogens in investigations of the race-specificity of host resistance. Annual Review of Phytopathology, v.14, p.97-119, 1976.

LUO, Y. \& ZENG, S.M. Simulation studies on epidemics of wheat stripe rust (Puccinia striiformis) on slow-rusting culivars and analysis of effects of resistance components. Plant Pathology, 44:340-349. 1995. Disponível em: <http://dx.doi. org/10.1111/j.1365-30591995.tb02786.x.>. Acesso em 15 out.2011: doi: 10.1111/j.1365-3059. 1995.tb02786.x.
MANNING, V. A.; CIUfFETTI, L. M. Localization of Ptr ToxA produced by Pyrenophora tritici-repentis reveals protein import into wheat mesophyll cells. Plant Cell, v. 17, p. 3203-3212, 2005. Disponível em: < http://dx.doi.org/10.1105/tpc.105.035063>. Acesso em: 25 nov. 2011. doi: 10.1105/tpc.105.035063.

MENEGON, A.P.; FORCELINI, C.A.; FERNANDES, J.M.C. Expansão de lesão por manchas foliares em cevada e sua interação com a aplicação foliar de fungicidas. Fitopatologia Brasileira, v. 30, n. 2, p. 134-138, 2005. Disponível em: <http:// dx.doi.org/10.1590/S0100-41582005000200005>. Acesso em: 17 nov.2011. doi:_10.1590/S0100-41582005000200005

PICININI, E.C.; FERNANDES, J.M.C,. Efeito de diferentes fungicidas sobre o rendimento de grãos, sobre o peso hectolitro e sobre o controle da Ferrugem da folha (Puccinia recondita f.sp. tritici) em trigo, cultivar 'BR 34'. Fitopatologia Brasileira, v. 20, p. 319, 1995.

REIS, E.M. \& CASA, R.T. Doenças dos cereais de inverno: diagnose, epidemiologia e controle. 2.ed. rev. atual. Lages: Ed. Graphel, 176 p. 2007.

REIS, E.M.; CASA, R.T.; DANELLI, A.L.D. Doenças do trigo: mancha-amarela da folha. São Paulo: Bayer S.A., 2011. 18p.

REUNIÃO DA COMISSÃO BRASILEIRA DE PESQUISA DE TRIGO E TRITICALE DA REGIÃO SUL (2.: 2008: Passo Fundo, RS). Informações técnicas para Trigo e Triticale Safra 2009. Passo Fundo - RS 1 a 3 julho de 2008: Embrapa Trigo 2009. 172p. 